\title{
Trasplante pancreático
}

\section{Pancreatic transplant}

\author{
M. C. Montiel, F. Pardo, F. Rotellar, V. Valentí, C. Pastor, J. Álvarez Cienfuegos
}

\section{RESUMEN}

La diabetes mellitus constituye una preocupación sanitaria de primer orden, dado el alto índice de morbimortalidad asociada. El objetivo para frenar el avance de sus complicaciones, antes de que éstas sean irreversibles, se basa en un control metabólico correcto. La alta tasa de morbilidad asociada a la cirugía del trasplante vascularizado de páncreas y el alto índice de rechazo ha constituido durante tres décadas un obstáculo para que se considerara a éste como una alternativa válida en el tratamiento de estos pacientes. El trasplante de páncreas hoy día ha pasado a ocupar un lugar primordial, gracias a los nuevos regímenes de inmunosupresión y al perfeccionamiento de la técnica quirúrgica.

En este capítulo revisamos la evolución del trasplante de páncreas desde sus inicios y su situación actual.

Palabras clave. Cirugía pancreática. Trasplante de páncreas. Islotes pancreáticos.

An. Sist. Sanit. Navar. 2006; 29 (Supl. 2): 113-124.

\begin{abstract}
Diabetes mellitus is a health concern of the first order, given the high level of associated morbidity and mortality. The objective, in order to slow down the advance of its complications before they become irreversible, is based on correct metabolic control. The high rate of morbidity associated with the surgery of the vascularized pancreas transplant and the high index of rejection have for three decades formed an obstacle to this being considered a valid alternative in the treatment of these patients. Nowadays the pancreas transplant has come to occupy a key position, thanks to the new regimes of immunosuppression and to the perfection of surgical techniques.

In this article we review the evolution of the pancreas transplant from its beginnings to its present state.
\end{abstract}

Key words. Pancreatic surgery. Pancreas transplant. Pancreatic islet.
Dpto. de Cirugía General. Clínica Universitaria. Pamplona. Navarra.

\section{Correspondencia:}

Clínica Universitaria de Navarra

Avda. Pío XII, 36

31008 PAMPLONA

Tfno. 948255400

Fax. 948296500 


\section{INTRODUCCIÓN}

La Diabetes Mellitus (DM) constituye una de las principales preocupaciones sanitarias a escala mundial. Existen 190 millones de diabéticos en el mundo. En España esta enfermedad afecta a dos millones de personas, entre el 5 y el $6 \%$ de la población (ONT), siendo su tendencia al alza. La DM está asociada con complicaciones devastadoras que incrementan la morbilidad y mortalidad de dichos pacientes. Constituye la principal causa de ceguera en los países desarrollados y de insuficiencia renal crónica (entre un 20\% y 30\% desarrollará enfermedad renal a lo largo de su vida) ${ }^{1}$. Además los pacientes que la padecen tienen mayor probabilidad de infarto agudo de miocardio, principal causa de muerte en los diabéticos tipo 2, y de hemorragia cerebral, responsable de un $15 \%$ de la mortalidad. Además de ser la responsable de más de la mitad de amputaciones de miembros que se realizan, afectando hasta el $25 \%$ de los diabéticos.

Por ello la DM, junto a sus complicaciones, supone uno de los mayores gastos sanitarios en los países occidentales. Se estima que entre el 6,3 y el $7,4 \%$ del presupuesto sanitario español se dedica a esta enfermedad.

El objetivo en el tratamiento de la diabetes es conseguir valores de glucemias normales, y con ello, un perfecto control metabólico. En 1993, la DCCT (Diabetes Control and Complications Trial Research Group) establece que el tratamiento insulínico intensivo presenta ventajas evidentes con respecto al tratamiento convencional, en cuanto a una disminución del riesgo de complicaciones. Sin embargo, no es capaz de normalizar por completo el nivel de glucemia en sangre, con lo que continúa existiendo riesgo de desarrollo de complicaciones (dos terceras partes de los pacientes tratados con terapia intensiva presentan progresión de su nefropatía diabética, así como de otras complicaciones microvasculares). Así mismo, afirman que el trasplante de páncreas puede ser la mejor opción terapéutica en casos seleccionados ${ }^{2}$.

El trasplante de páncreas es la única terapia que ha demostrado su efectividad para un control metabólico correcto, consi- guiendo valores fisiológicos de hemoglobina glicosilada (nivel medio de hemoglobina glicosilada $5,5 \%$, sin casi episodios de hipoglucemia, frente a un $7 \%$ con el régimen intensivo de insulina). Hoy día, gracias a la mejoría de la técnica quirúrgica y al desarrollo de nuevos regímenes de inmunosupresión, el trasplante de páncreas ha alcanzado un alto porcentaje de éxitos.

Paralelamente el trasplante de islotes ha resurgido con el protocolo de Edmonton, publicado por J. Shapiro en julio del 2000 , donde el $80 \%$ de los enfermos continuaban sin insulina al año de la realización del procedimiento. Constituye todavía una terapia experimental, debiéndose realizar sólo en estudios controlados. La comunidad científica tiene depositadas muchas esperanzas en conseguir su éxito en la práctica clínica, ya que además de conseguir un control glucémico correcto, evitaría todas las complicaciones quirúrgicas que surgen con el trasplante vascularizado de páncreas.

\section{HISTORIA DEL TRASPLANTE DE PÁNCREAS}

El 16 de diciembre de 1966 se realizó el primer trasplante de páncreas. En la Universidad de Minesota, William Kelly y Richard Lillehei trasplantaron un segmento de páncreas junto con riñón procedente de un donante cadáver en una mujer de 28 años con diabetes mellitus y fracaso renal. El periodo libre de insulina fue de 6 días. En el séptimo día postoperatorio, la paciente presentó una fístula pancreática que requirió una relaparotomía y extracción del injerto. La receptora falleció a los 13 días de la segunda intervención por embolia pulmonar ${ }^{3}$.

La evolución del trasplante de páncreas ha sido más tórpida que la del resto de órganos sólidos. Su aceptación y tasa de éxito actual se debe a los avances en la técnica quirúrgica, al desarrollo de soluciones de preservación, y a la introducción de nuevos fármacos inmunosupresores.

En cuanto a la técnica quirúrgica, el principal debate se ha focalizado en el trasplante de páncreas exocrino. Todavía no se ha identificado la técnica ideal para el manejo de las secreciones exocrinas. 
Lillehei realizó en sus primeros cuatro casos duodenostomía, y en sus ocho siguientes, drenaje interno mediante duodenoyeyunostomía en Y de Roux. En 1973, Gliedman y col publicaron los resultados de cuatro trasplantes de segmentos pancreáticos en los que el conducto pancreático se anastomosó al uréter ipsilateral. Ideó esta técnica para evitar trasplantar el duodeno, realizar una anastomosis intestinal o mantener una fístula pancreática externa. Dos nuevas técnicas fueron introducidas a mitad y finales de la década de los 70: el drenaje abierto y la inyección ductal. En la primera técnica la secreción pancreática era absorbida por el peritoneo, sin activación de sus enzimas, ya que no entraban en contacto con los componentes de la luz intestinal. Los primeros casos se realizaron en el Guys Hospital de Londres, seguidos por la Universidad de Minesota. En 1978, Dubernard y col expusieron una técnica donde el conducto pancreático de un injerto segmentario de páncreas era sellado mediante un polímero sintético, el neopreno. El primer trasplante donde se utilizó dicha técnica fue en Lyon. Hasta principios de la década de los 80 , la técnica de la inyección ductal fue la más empleada para el drenaje de las secreciones exocrinas, particularmente en Europa.

El primer Registro Internacional de Trasplante de Páncreas e Islotes tuvo lugar en Lyon en 1980. Hasta entonces tan sólo se habían realizado 105 trasplantes, 53 en EEUU y 52 fuera de este país. Los centros transplantadores eran en EEUU, la Universidad de Minesota en Mineápolis y el hospital de Montefiore en Nueva York; en Europa, el Huddinge Hospital de Estocolmo, Suecia, y el hospital Edouard Herriot en Lyon, Francia. Por entonces, la Universidad de Minesota utilizaba la técnica del drenaje abierto a cavidad, el hospital de Montefiore el drenaje ureteral, el hospital de Huddinge el drenaje entérico y el hospital de Edouard Herriot la inyección ductal.

En 1983, Hans Sollinger en la Universidad de Wisconsin dio a conocer una técnica que ha sido la más practicada dentro de esta disciplina: el drenaje vesical. Ésta aportaba una baja incidencia de complicaciones quirúrgicas (en particular bajo índice de fugas), y además permitía detectar en fase precoz el rechazo del injerto pancreático mediante la determinación de un descenso de amilasa en orina. Fue la técnica más utilizada desde mediados de los ochenta hasta mediados de los noventa.

A finales de los noventa hubo un nuevo cambio a favor del drenaje entérico. Este era más fisiológico, mejoraba las terapias inmunosupresoras y antimicrobianas, favoreciendo así una reducción en el número de complicaciones así como la posibilidad de rechazo.

Otro tema debatido ha sido el uso de un segmento pancreático o el injerto completo junto con el duodeno. A favor del primero estaba que era una técnica más rápida y sencilla, por el contrario existía mayor riesgo de fugas pancreáticas y una reducción en el número de islotes trasplantados. En un primer momento se aplicó fundamentalmente el trasplante del injerto completo. El segmento pancreático se hizo más común a finales de la década de los setenta y principios de los ochenta. Desde mediados de los años ochenta el trasplante completo de páncreas ha sido la técnica estándar. Sin embargo, el segmento pancreático sigue estando vigente en relación con el donante vivo. En el 2001, la Universidad de Minesota introdujo la pancreatectomía distal laparoscópica de donante vivo como opción de trasplante pancreático ${ }^{3}$.

El desarrollo de nuevos protocolos de inmunosupresión ha mejorado los resultados del trasplante de páncreas. Hasta 1980 el régimen de inmunosupresión consistía en azatioprina y esteroides. Con la llegada de la ciclosporina se utilizó una terapia triple, que se ha mantenido hasta que a mediados de los años noventa la FDA (Food and Drug Administration) permitió el uso del tacrolimus y el mofetil micofenolato (MMF). A finales de los años noventa el $80 \%$ de los pacientes trasplantados de páncreas mantenían su régimen de inmusupresión con tacrolimus. Siendo la combinación de éste con el MMF la terapia más generalizada.

La selección del candidato ha sido siempre un elemento muy importante en la historia del trasplante de páncreas. De hecho en muchos centros el trasplante de páncreas ha estado limitado a pacientes 
con fracaso renal que precisaban trasplante renal y que, por tanto, la inmunosupresión era obligada (trasplante simultáneo de riñón-páncreas, SPK), o en aquellos pacientes que ya tenían un injerto renal (riñón seguido de páncreas, PAK). Esta tendencia surgió tras observar que los trasplantes de páncreas aislados en pacientes con buena función renal estaban asociados a una mayor tasa de rechazo, con tan sólo un $50 \%$ de supervivencia del injerto a los 5 años. Sin embargo, el perfeccionamiento de la técnica quirúrgica junto con los exitosos regímenes terapéuticos ha permitido expandir los criterios para el trasplante de páncreas incluido aquellos pacientes sin fracaso renal.

\section{RECEPTOR}

La selección de los candidatos a trasplante pancreático debe ser muy rigurosa, ya que el éxito de la técnica se debe en gran parte a la selección de los pacientes. Debemos tener en cuenta que las complicaciones de la diabetes deben estar en fase reversible para que éstas puedan mejorar, o en todo caso, estabilizarse. Además los pacientes con varias complicaciones diabéticas severas no serían buenos candidatos a trasplante dado el alto riesgo quirúrgico, y la escasa mejoría experimentada en su calidad de vida.

\section{Indicaciones}

\section{Trasplante riñón-páncreas}

El trasplante simultáneo de riñón-páncreas representa el 88\% de todos los trasplantes de páncreas realizados. La evaluación de un receptor para SPK es similar a la que se lleva a cabo para el trasplante de riñón aislado, con algunas modificaciones ${ }^{2}$.

1. Los pacientes con diabetes mellitus tipo 1, péptido $\mathrm{C}<0,5 \mathrm{ng} / \mathrm{ml}$. Los pacientes con diabetes tipo 2 deberán ser analizados individualmente.

2. Edad menor de 50 años, valorando individualmente a los pacientes mayores.

3. Criterios habituales para trasplante renal (En Europa, aclaramiento de creatinina $<30 \mathrm{ml} / \mathrm{min}$ ).

4. Ausencia de vasculopatía periférica y coronariopatía severas.
5. Ausencia de neuropatía motora o autonómica incapacitante.

6. Ausencia de trastornos psiquiátricos o psicológicos severos, así como capacidad para entender los que supone un trasplante de páncreas.

\section{Trasplante de páncreas después de riñón}

Representa aproximadamente el 10\% de todos los trasplantes de páncreas. Para los centros con más experiencia la supervivencia del injerto renal es superior con el PAK que con el trasplante renal aislado. Sin embargo, en un estudio retrospectivo en el período 1995-2000, la mortalidad de los pacientes con PAK fue superior a la de los pacientes que permanecían en lista de espera. Por tanto, este tipo de trasplante debe ofrecerse a aquellos pacientes trasplantados renales con diabetes tipo 1, que cumplan los mismos criterios que para el SPK y que además mantengan un mal control de su diabetes. Estos pacientes deben cumplir los siguientes requisitos ${ }^{2}$ :

1. Diabetes mellitus tipo1, péptido $\mathrm{C}<0,5$ $\mathrm{ng} / \mathrm{ml}$.

2. Trasplante renal previo de donante vivo o donante cadáver.

3. Función estable del injerto renal, con aclaramiento de creatinina $>40 \mathrm{ml} / \mathrm{min}$.

4. Diabetes inestable o mal control metabólico (Hb Alc > 8\%).

5. Empeoramiento de las lesiones crónicas a pesar del tratamiento óptimo, y tras los ajustes de la inmunosupresión.

6. Fallo del injerto pancreático después de un trasplante de riñón-páncreas.

\section{Trasplante de páncreas aislado}

Hasta 1997 tan sólo se habían realizado alrededor de 100 trasplantes de páncreas aislados. Los candidatos son aquellos pacientes con diabetes tipo 1 con un aclaramiento de creatinina $>60 \mathrm{ml} / \mathrm{min}$, y una proteinuria $<2 \mathrm{~g} / 24 \mathrm{~h}$, que presenten los siguientes criterios ${ }^{2}$ :

1. Complicaciones metabólicas frecuentes, como la hipoglucemia, hiperglucemia, cetoacidosis, que requieran asistencia sanitaria. 
2. Problemas clínicos y emocionales derivados de la administración de la terapia insulínica que resulten incapacitantes.

3. Fallo en el control de la insulinoterapia para prevenir complicaciones agudas.

\section{Trasplante de páncreas en la diabetes tipo 2}

Se trata de una indicación excepcional. Los pacientes deben cumplir los criterios aceptados para el trasplante en los pacientes con diabetes tipo 1, junto con los siguientes requisitos: cinco años o más en tratamiento con insulina, necesidades de insulina no superiores a una unidad $/ \mathrm{kg} / \mathrm{día}$, y $\mathrm{IMC} \leq 30 \mathrm{Kg} / \mathrm{m}^{2}$.

\section{Contraindicaciones}

Se consideran contraindicaciones de trasplante páncreas: infección activa, alteraciones de la coagulación, prueba cruzada positiva para células $\mathrm{T}$ con suero actual, drogadicción o alcoholismo activos, coronariografía con lesiones no corregibles, fracción de eyección $<50 \%$, infarto de miocardio reciente, neoplasia, obesidad severa, incumplimiento de tratamiento previo, enfermedad psiquiátrica. Son contraindicaciones relativas: IMC $>30$, hemorragia retiniana reciente, fumador activo, serología positiva VHC y VHB, los anticuerpos citotóxicos circulantes >25\% requiere la selección de un donante más idóneo.

\section{DONANTE DE PÁNCREAS E ISLOTES}

Las condiciones exigidas para un donante de páncreas son más cautelosas que para un trasplante renal. El período de edad recomendado oscila entre 10 y 45 años. En la era de la ciclosporina se comprobó que donantes por encima de 45 años se relacionaban con un aumento significativo de trombosis vascular, infección abdominal, re-intervención quirúrgica y fístula duodenal. Sin embargo, en la etapa del tacrolimus los estudios no han mostrado diferencias estadísticamente significativas en relación con la edad. Actualmente la edad superior a 45 años no es una contraindicación, pero sí merece una valoración rigurosa.
El donante debe tener un peso mínimo de $30 \mathrm{~kg}$, ya que el páncreas es un órgano de bajo flujo, y en aquellos páncreas con vasos de menor calibre se favorece la trombosis vascular y por tanto, la pérdida del injerto. Por otro lado, un IMC > 30 es una contraindicación ya que suele implicar una degeneración grasa del páncreas, con un aumento en la incidencia de pancreatitis, trombosis e infección.

El donante ideal es un individuo fallecido por traumatismo craneoencefálico o por hemorragia intracraneal secundaria a malformaciones vasculares. Sin embargo, la frecuencia de estos candidatos está decayendo a favor de donantes, más añosos, donde la existencia de comorbilidades como la HTA y la arteriosclerosis podrían influir en los resultados del trasplante. El estado de los vasos ilíacos es fundamental para una correcta reconstrucción vascular y su correcto funcionamiento posterior. En la Universidad de Minesota se obtuvo como factor de riesgo independiente para trombosis vascular aquellos donantes fallecidos por accidentes cerebrovasculares. La muerte por intoxicación no constituye una contraindicación salvo en el caso del metanol, que puede incrementar los niveles de amilasemia, producir pancreatitis $\mathrm{o}$ necrosis pancreática.

La hiperglucemia es un hallazgo común en los pacientes con muerte encefálica, ligada a la situación de estrés y la producción de hormonas como esteroides endógenos y catecolaminas, así como a la administración exógena de soluciones glucosadas y fármacos. La literatura sostiene que la hiperglucemia no es una contraindicación para el trasplante de páncreas, en ausencia de historia de insuficiencia endocrina.

La elevación aislada de los niveles de amilasa plasmática, en ausencia de otras comorbilidades no constituye una contraindicación para la donación. Así, la hiperamilasemia está frecuentemente asociada a donantes fallecidos por traumatismo craneoencefálico, como consecuencia del traumatismo directo sobre las glándulas salivares. Existen otras circunstancias en las que la hiperamilasemia sí justifica la contraindicación en la donación como el 
traumatismo directo sobre el páncreas, el cáncer metastásico, o la insuficiencia renal severa.

Con la introducción de la solución de Wisconsin, el tiempo de isquemia fría aceptado para que el injerto de páncreas pueda funcionar con normalidad es hasta de 30 horas. Aunque existen diversos estudios que han observado un aumento en la incidencia de infecciones intra-abdominales y de trombosis en aquellos injertos con tiempos de isquemia prolongados. Según recoge el RITP, en los últimos años el tiempo medio de isquemia fría ha sido de 15 horas para el trasplante aislado de páncreas y de 13 horas para el simultáneo páncreas-riñón.

Está ampliamente aceptado que la correcta reversión de una parada cardiorrespiratoria no constituye una contraindicación para la extracción pancreática. Sí debemos prestar especial atención al uso de drogas vasoactivas, y a la necesidad de altas dosis para mantener estabilidad hemodinámica.

\section{TÉCNICA QUIRÚRGICA}

\section{Extracción}

A continuación describiremos la técnica de extracción combinada de hígadopáncreas con partición in situ. En caso de inestabilidad hemodinámica, se debe realizar la extracción rápida o en bloque, para poder perfundir en el menor tiempo posible. Se realiza una incisión xifopubiana, con sección del esternón y abertura del pericardio. Es opcional la incisión transversa bilateral a nivel abdominal, que favorece la exposición completa de toda la cavidad. Se procede a un examen cuidadoso de todos los órganos para identificar cualquier patología que contraindique la extracción. El primer paso consiste en realizar una disección de la aorta y cava infrarrenales, dejando pasadas ligaduras que permitan una rápida canulación en caso de inestabilidad. Se accede al saco menor seccionando el ligamento gastrocólico, y se inspecciona toda la superficie anterior del cuerpo y cola del páncreas; esto junto con la palpación de la cabeza pancreática nos permite realizar una primera valoración sobre el estado del órgano.
Debemos identificar las posibles variantes arteriales hepáticas, presentes en el 10 al $30 \%$ de los casos, ya que pueden influir en el tipo de procedimiento. El ligamento gastrohepático es disecado un centímetro por encima del borde superior del páncreas, se secciona el colédoco, ligando su borde distal en el lado pancreático. La vesícula biliar se abre a nivel del fundus y se procede al lavado con suero de la vía biliar. Se identifica la arteria hepática propia y se diseca hasta el tronco celíaco, ligando a su paso la arteria gastroduodenal. También se identifican y ligan la arteria gástrica izquierda y la vena coronaria, así como todos los vasos linfáticos en el borde superior del páncreas. La arteria esplénica se controla pasando ligaduras sin anudar. El último paso a este nivel es la disección de unos dos centímetros de porta, a mitad de camino entre el páncreas y el hígado.

Tras la disección de todo el pedículo hepático, se realiza la maniobra de Kocher movilizando todo el duodeno y la cara posterior de la cabeza pancreática, y se abre camino hacia la aorta y la cava infrahepáticas. La disección del páncreas se debe hacer mediante la técnica de "no-touch", para ello se completa la sección de los vasos cortos gastroesplénicos y se moviliza todo el colon transverso desde el ángulo hepático hasta el ángulo esplénico. Posteriormente se seccionan todos los ligamentos que fijan el bazo al retroperitoneo, y se utiliza éste como mango, para minimizar la manipulación del páncreas. Éste acaba separándose del riñón y la glándula suprarrenal izquierda, así como de las fijaciones del cuerpo y la cola al retroperitoneo. Se exponen finalmente el tronco celíaco, la arteria mesentérica superior y la vena renal izquierda.

La perfusión vía portal es opcional, en el caso de la técnica clásica se debe disecar la vena mesentérica inferior unos $5 \mathrm{~cm}$ antes de su entrada en el páncreas, para permitir la canulación.

A través de la sonda nasogástrica se introducen $250 \mathrm{ml}$ de povidona yodada, entonces se secciona el duodeno situado a continuación del píloro, así como a nivel de la cuarta porción. Esta maniobra puede también realizarse justo antes de la extrac- 
ción del órgano para que no se distienda o se acumulen secreciones biliopancreáticas y digestivas.

A continuación se procede a la movilización del hígado, liberándolo de sus fijaciones al diafragma a través de los ligamentos triangulares. Entonces el hígado se rechaza hacia línea media, y se diseca la vena cava intrahepática en dirección caudal hasta las venas renales, identificando y ligando la vena suprarrenal derecha.

Una vez la disección está completada a nivel intratorácico y abdominal, se administra heparina intravenosa ( $\geq 70 \mathrm{U} / \mathrm{kg})$, se clampa la aorta supracelíaca y se comienza con la perfusión de la solución de Wisconsin (2L por aorta y 1L por vía portal aproximadamente).

Tras finalizar la perfusión, el páncreas y el hígado son separados in situ. La arteria esplénica se divide justo después de su nacimiento en el tronco celíaco. La aorta a nivel de la arteria mesentérica superior se secciona lateralmente para visualizar en todo momento el nacimiento de las arterias renales. Y el parche aórtico se divide en dos, el hepático con el tronco celíaco y el pancreático con la arteria mesentérica superior. La vena cava infrahepática se secciona por encima de los orificios de las venas renales. La vena cava suprahepática se divide junto con el diafragma que la rodea. Por último la porta se divide a medio camino entre el hígado y el páncreas. La hepatectomía está entonces completada, y a continuación se procede también a la extracción del páncreas.

El órgano se introduce en una bolsa estéril con solución de Wisconsin a $4^{\circ} \mathrm{C}$. Esta bolsa se protege introduciéndola en otras dos bolsas y es transportada al hospital donde espera el receptor, para realizar la cirugía de banco. Las arterias ilíacas comunes junto con sus bifurcaciones también se extirpan y se reparten entre el injerto pancreático y el hepático.

\section{Cirugía de banco}

Durante la cirugía de banco es importante mantener el órgano en la solución de preservación a $4^{\circ} \mathrm{C}$. Si no se ha realizado previamente, se referencia la arteria esplénica y la porta con sutura de prolene $6 / 0$, para impedir su retracción en el páncreas. Se prosigue con la esplenectomía, ligando arteria y vena esplénica, así como toda la grasa incluida en el hilio. El duodeno debe disecarse hasta facilitar la sutura en tres planos, uno interior con grapas y dos exteriores con puntos sueltos de seda. Posteriormente mediante la introducción de un abbocath, se lava con una solución de anfotericina B. La vena porta debe disecarse hasta la bifurcación esplenomesentérica. Por último se utiliza el injerto de la arteria ilíaca para el restablecimiento del flujo arterial, anastomosando la ilíaca interna con la esplénica y la externa con la arteria mesentérica superior. Así el injerto pancreático está listo para el implante ${ }^{2}$.

\section{Cirugía en el receptor ${ }^{3}$}

La práctica habitual en el receptor consiste en el implante de todo el órgano completo, situado a nivel intraabdominal. El trasplante de un segmento pancreático es la única opción válida para el donante vivo. Aunque técnicamente es más sencillo, diferentes grupos han comprobado un peor control metabólico, con una mayor incidencia de intolerancia a la glucosa y un peor perfil lipoproteico.

\section{Drenaje vesical vs entérico}

Para el manejo de la secreción exocrina del injerto pancreático existen actualmente dos alternativas, el drenaje vesical y el drenaje entérico. El drenaje vesical introducido por Sollinger mejoró la técnica quirúrgica y disminuyó en gran medida el índice de complicaciones graves postrasplante. Se considera una técnica segura para el drenaje de las secreciones pancreáticas. Por ello, según la IPTR, en 1995 se practicó dicho procedimiento en más del $90 \%$ de los trasplantes realizados. Sin embargo, existen complicaciones metabólicas y urinarias que obligan a la conversión a drenaje entérico hasta en un 15-25\% de los pacientes trasplantados. La pérdida de 1-2 litros de secreciones duodenales y pancreáticas lleva a una disminución del bicarbonato y a trastornos hidroelectrolíticos, con resultado de acidosis metabólica crónica y deshidratación, pudiendo llegar a requerir en casos graves asistencia médica para reposición 
de fluidos y bicarbonato. Las complicaciones urológicas son relativamente frecuentes, derivadas de la activación de enzimas pancreáticos, que provocan una irritación constante sobre el epitelio transicional. Están incluidas la cistitis y uretritis química, infecciones, hematuria, cálculos vesicales, y episodios recurrentes de pancreatitis, relacionados con la existencia de reflujo.

El avance en la técnica quirúrgica ha hecho reconsiderar el uso del drenaje entérico, más fisiológico, descrito por Lillehei. El grupo de Stockholm ha simplificado la técnica mediante el drenaje directo, y omitiendo el uso del catéter ductal pancreático. El análisis de seis estudios diseñados para comparar ambas técnicas, considera mejor el uso del drenaje entérico con un nivel de recomendación grado B. Actualmente es el procedimiento estándar en casos de trasplante simultáneo en la mayoría de centros especializados ${ }^{4}$. Para el trasplante aislado de páncreas es una opción menos válida, ya que no permitiría realizar una monitorización de la amilasa urinaria, crucial para la detección de rechazo del injerto.

Los resultados publicados en cuanto a la supervivencia del paciente e del injerto son similares en ambos grupos, en caso de trasplante simultáneo de riñón-páncreas. Sin embargo, en el trasplante de páncreas aislado la tasa de supervivencia del injerto sigue siendo mayor con el drenaje vesical.

\section{Drenaje venoso sistémico vs portal}

El drenaje venoso sistémico se asocia a hiperinsulinismo, aunque los niveles de glucemia sean comparables con ambas técnicas. El drenaje venoso portal es más fisiológico, con niveles de insulina más bajos y con las posibles ventajas de un mejor control metabólico. El hiperinsulinismo periférico se ha asociado con arteriosclerosis, y el hipoinsulinismo portal con trastornos de las lipoproteínas. A pesar de esto, aún no existe evidencia de que el drenaje venoso sistémico conlleve un mayor riesgo vascular en dichos pacientes. El control metabólico es comparable en ambos grupos. Basados en tres estudios de nivel $1 \mathrm{~b}$ y $2 \mathrm{a}$, se puede concluir que al drenaje venoso portal ofrece una leve ventaja sobre el sistémi- co, así la elección de drenaje venoso portal puede ser sugerida, con un grado de recomendación $\mathrm{C}^{4}$. Se pueden considerar como técnicas complementarias; el drenaje sistémico en pacientes obesos, con venas de pequeño calibre y con mesenterio muy denso, y el drenaje portal en pacientes con arteriosclerosis severa, cirugía pélvica previa e injerto arterial corto.

\section{COMPLICACIONES QUIRÚRGICAS}

Es posible observar las complicaciones comunes relacionadas con la cirugía mayor abdominal, como íleo postoperatorio, obstrucción intestinal, colecistitis, gastroparesia, infección o dehiscencia de herida quirúrgica. Aunque en este apartado mencionaremos sólo las complicaciones específicas derivadas de esta cirugía ${ }^{5}$.

\section{Complicaciones vasculares}

1. Trombosis. Es la complicación quirúrgica más frecuente, los estudios más recientes refieren una tasa actual de trombosis del $6 \%$ en trasplante simultáneo riñón-páncreas, $7 \%$ en trasplante de páncreas después de riñón, y un $9 \%$ en trasplante de páncreas aislado. Supone casi la mitad de los fallos no inmunológicos del injerto. Se manifiesta en las dos primeras semanas hasta en el $90 \%$ de los casos. El paciente puede presentar dolor abdominal. Se detecta hiperglucemia de reciente aparición. En caso de drenaje vesical, la desaparición o disminución del nivel de amilasa en orina puede ser diagnóstica. El diagnóstico se confirma mediante un eco-doppler. La pancreatectomía del injerto suele ser el tratamiento habitual tras una trombosis aguda del injerto.

2. Hemorragia. Mientras que una hemorragia leve puede ser tratada de forma conservadora, no es infrecuente la relaparotomía precoz secundaria a hemorragia intra-abdominal. Un factor de riesgo importante es la utilización de anticoagulación.

3. Pseudoaneurisma micótico. Se produce siempre en el contexto de una infección intra-abdominal. Los signos son 
sepsis, puede existir trombosis de la vena ilíaca ipsilateral, pérdida o disminución del pulso de la extremidad afecta, e incluso un sangrado masivo intraabdominal. La pancreatectomía del injerto es casi siempre necesaria, y la extremidad implicada puede requerir algún procedimiento de revascularización.

\section{Infecciones intra-abdominales (IIA)}

Supone una complicación seria que puede reducir de forma significativa la supervivencia del injerto y del paciente. Causas responsables de IIA son la pancreatitis por lesión de reperfusión, contaminación y traslocación bacteriana en el duodeno del donante, fuga anastomótica y necrosis del injerto. La mayoría de los centros utilizan el fluconazol como profilaxis antifúngica y la combinación del imipenem o la piperacilina junto con la vancomicina como profilaxis bacteriana.

\section{Pancreatitis del injerto}

Se manifiesta mediante una hiperamilasemia prolongada. Se ha relacionado con la inestabilidad hemodinámica, administración de drogas vasoactivas, volumen y presión en la perfusión de la solución de preservación, y lesión por reperfusión. En el caso de drenaje vesical, la causa más común de pancreatitis es por reflujo por retención de orina. El octreótide puede ser utilizado para la profilaxis o el tratamiento de esta complicación.

\section{Fuga anastomótica}

La incidencia de fuga en el trasplante de páncreas con drenaje vesical es mayor que en caso de drenaje entérico, sin embargo la incidencia de fuga asociada a pérdida del injerto es mayor en caso de drenaje entérico. Existe hiperamilasemia hasta en un $50 \%$ de los pacientes. La técnica utilizada como gold estándar es el TC abdominal con inyección de contraste vesical para el trasplante con drenaje vesical, y el TC abdominal con contraste oral para el drenaje entérico. El porcentaje de éxito del tratamiento conservador es bastante bajo, un $12 \%$ en caso de drenaje vesical, siendo necesaria la reparación primaria de la fuga anastomótica hasta en un $66 \%$ de los casos, o en su defecto la conversión entérica. En caso de fuga por drenaje entérico la laparotomía exploratoria es casi siempre necesaria para un adecuado manejo del paciente.

\section{Complicaciones relacionadas con el drenaje vesical}

Debido a la pérdida mantenida de fluidos y bicarbonato, el paciente presenta a menudo deshidratación y acidosis metabólica. La ingesta oral de bicarbonato y líquidos suele ser suficiente para recobrar la normalidad, siendo necesaria a veces la conversión entérica. Las complicaciones más serias son las urológicas, en orden de frecuencia: infección recurrente del tracto urinario, hematuria crónica, fuga urinaria y lesiones uretrales. La infección del tracto urinario suele tratarse con tratamiento antibiótico, a veces puede ser necesaria la cistoscopia para retirada de cuerpos extraños como el material de sutura, y en caso muy raro la conversión entérica. La hematuria crónica se puede controlar en la mayoría de los casos con fulguración mediante cistoscopia. La fuga anastomótica, si es leve puede ser tratada de forma conservadora con una sonda de Foley, si fracasa este tratamiento es mandatorio la intervención quirúrgica. La mayoría de los pacientes con complicaciones uretrales suelen precisar la conversión entérica para la desaparición de los síntomas.

\section{RESULTADOS}

Según el Registro Internacional de Trasplante de Páncreas, en el trasplante simultáneo de riñón-páncreas, la supervivencia al año del paciente, el injerto pancreático y renal ha mejorado de un $90 \%, 74 \%$ y $83 \%$ respectivamente en el periodo 1987-1989, a un $95 \%, 83 \%$ y $88 \%$ durante el periodo 1996 2000, en los pacientes tratados en EEUU (Tabla 1) ${ }^{6}$. Mientras que en el trasplante de páncreas seguido de riñón y en el páncreas aislado la supervivencia del injerto de páncreas al año ha sido en este último periodo de $73 \%$ y $70 \%$ respectivamente ${ }^{7}$ (Tabla 2 ).

\section{SUPERVIVENCIA DEL PACIENTE}

Estudios prospectivos actuales y estudios retrospectivos amplios han demostrado que existe una mayor supervivencia en 
pacientes tratados mediante trasplante simultáneo páncreas-riñón frente a aquellos tratados mediante trasplante aislado de riñón. Aquellos pacientes diabéticos que desarrollan una insuficiencia renal crónica entre los 21 y 40 años tratados mediante trasplante simultáneo tienen una mejor expectativa de vida y una menor tasa de mortalidad anual que aquel grupo de pacientes con trasplante de riñón de donante cadáver o donante vivo ${ }^{8}$.

En un estudio observacional realizado en 124 centros de EEUU desde 1995 hasta 2000 , se observó que la supervivencia de los pacientes con trasplante aislado de páncreas era peor, con significación estadística, que la supervivencia de aquellos paciente que estaban en lista de espera ${ }^{9}$.

La ausencia de ensayos clínicos controlados representa una barrera para comprender y compara los riesgos y beneficios del trasplante aislado de páncreas y el trasplante de páncreas seguido de riñón. La mortalidad relacionada con el postoperatorio, sin aparentes beneficios de supervivencia a largo plazo, debería suavizar el entusiasmo existente para estos dos tipos de trasplante ${ }^{10}$.

\section{SUPERVIVENCIA DEL INJERTO RENAL}

La supervivencia del injerto renal en el trasplante simultáneo en pacientes con diabetes tipo 1 es comparable a la supervivencia del injerto renal en trasplante aislado de riñón de cadáver.

Sin embargo, diversas hipótesis sostienen que existe un claro beneficio para el riñón transplantado si existe una buena función del injerto pancreático. Los pacientes con trasplante simultáneo observados a los 2,5 años tras la cirugía, comparados con aquellos pacientes con trasplante aislado de riñón no presentan engrosamiento de la membrana basal glomerular (92\% vs 35\%) ni expansión del volumen mesangial ( $82 \%$ vs $12 \%$ ). Además, se ha observado que la progresión de la glomerulopatía en pacientes trasplantados de riñón puede detenerse a los dos años tras un trasplante de páncreas diferido.

\section{EFECTOS METABÓLICOS}

El trasplante de páncreas permite restaurar el nivel de glucosa en sangre y la respuesta bifásica de la insulina tras la estimulación con glucosa. Se obtiene una

Tabla 1. Supervivencia al año, 5 años y 10 años de paciente, e injertos de páncreas y riñón, en un estudio de 500 pacientes con trasplante simultáneo de páncreas-riñón, en la Universidad de Wisconsin entre 1986 y $1997^{6}$.

\begin{tabular}{lccc}
\hline & Paciente (\%) & Páncreas (\%) & Riñón (\%) \\
\hline 1 año & 96 & 88 & 89 \\
5 años & 89 & 78 & 80 \\
10 años & 76 & 67 & 67 \\
\hline
\end{tabular}

Tabla 2. Supervivencia del injerto pancreático al año y 3 años según el tipo de trasplante de páncreas realizado, en EEUU, recogido en el Registro Internacional de Trasplante de Páncreas entre enero de 1996 y julio de $2000^{6}$.

\begin{tabular}{lccc}
\hline & 1 año (\%) & 3 años (\%) & n \\
\hline Trasplante simultáneo de páncreas-riñón & 84 & 77 & 3370 \\
Trasplante de páncreas seguido de riñón & 73 & 58 & 572 \\
Trasplante aislado de páncreas & 70 & 58 & 254 \\
\hline
\end{tabular}


normalización de la hemoglobina glicosilada en semanas o meses tras la cirugía. Aunque pueden ocurrir episodios de hipoglucemia, el coma hipoglucémico es excepcional.

La existencia de hiperinsulinismo se ha asociado al drenaje venoso sistémico, a una disminución del aclaramiento de insulina por el hígado, a los fármacos anticalcineurínicos y los esteroides, y a una supresión incompleta de insulina debida a la denervación existente en el injerto pancreático. Aunque el papel patogénico del hiperinsulinismo es aún controvertido, se ha asociado al desarrollo de arteriosclerosis y cardiopatía isquémica ${ }^{6}$.

El metabolismo lipídico tras un trasplante de páncreas mejora o al menos se mantiene en la mayoría de los estudios realizados.

\section{ENFERMEDAD CARDIOVASCULAR}

Se ha observado una progresión de la enfermedad establecida macrovascular a pesar de la realización satisfactoria del trasplante de páncreas, seguido de amputaciones, accidentes cerebrovasculares y cardiovasculares. La influencia del trasplante de páncreas sobre la evolución de la enfermedad vascular asintomática está aún por dilucidar.

Sin embargo, el trasplante de páncreas puede tener un efecto positivo en la función cardíaca. Se ha observado una mejoría precoz en los parámetros ecocardiográficos y en la normalización de la geometría del ventrículo izquierdo en el seguimiento a dos años de un grupo de pacientes sometidos a trasplante simultáneo. Además se consigue una reducción en la presión arterial, lo que beneficiaría a los pacientes con nefropatía diabética establecida.

\section{NEUROPATÍA}

Los pacientes diabéticos con neuropatía moderada que se someten a un trasplante de páncreas funcionante tienen una mayor supervivencia que aquellos no sometidos a trasplante o con un fallo precoz del mismo. Está descrita la recuperación de la conducción nerviosa sensitivomotora. Desde el punto de vista clínico, el paciente supera en un corto período de tiempo la polineuropatía dolorosa y el síndrome de piernas inquietas.

\section{RETINOPATÍA}

La DCCT demostró que la mejoría en los niveles de hemoglobina glicosilada reduce el riesgo de desarrollo o progresión de la retinopatía y el edema macular. En la mayoría de los estudios los pacientes sometidos a un trasplante de páncreas presentan en el momento del trasplante retinopatía proliferativa. Por esta razón, se tratan mediante coagulación panretiniana con láser. Esto podría justificar la estabilización de la retinopatía diabética tras el trasplante. Es necesario realizar estudios con mayor número de pacientes y con una completa evaluación oftalmológica previa al trasplante para conocer mejor los posibles efectos beneficiosos ${ }^{6}$.

\section{CALIDAD DE VIDA}

Conseguir una buena calidad de vida es uno de los objetivos principales en el trasplante de páncreas. Ésta se caracteriza por: (a) rehabilitación hacia una vida "normal" con un bienestar físico, psicológico y social, con una auto-percepción de normalidad, (b) mejora global en calidad de vida con percepción de control sobre su propio destino, (c) escasas restricciones que mejoren la sensación de bienestar e independencia. Gross y col revisaron diversos estudios sobre la calidad de vida tras el trasplante de páncreas, y encontraron una percepción más positiva de la salud, un incremento en la interacción social así como de la energía y vitalidad del paciente, comparado con aquellos pacientes en lista de espera o con pérdida del injerto. En el trasplante aislado de páncreas los resultados en cuanto a calidad de vida son menos claros. La ausencia de randomización y de grandes estudios comparativos observacionales dificulta la evaluación de este parámetro. A corto plazo, la mejora en la calidad de vida y la prevención o estabilización de la morbilidad y mortalidad asociada a las complicaciones de la diabetes hacen al trasplante de páncreas una importante opción terapeútica en pacientes seleccionados con diabetes insulín-dependiente ${ }^{4}$. 


\section{TRASPLANTE DE ISLOTES PANCREÁTICOS (TIP)}

El TIP ha sido considerado siempre como el tratamiento ideal para los pacientes con diabetes mellitus tipo 1, pero nunca se consiguió llevar a la práctica clínica. Desde la publicación del protocolo de Edmonton en el año 2000, en la Universidad de Alberta, Canadá, esta realidad está más cercana. Todos los pacientes que recibieron un trasplante de islotes de dos a cuatro donantes obtuvieron independencia insulínica. Actualmente más de 45 centros en todo el mundo realizan ensayos clínicos sobre el trasplante de islotes ${ }^{11}$.

Para obtener el aislamiento satisfactorio de islotes pancreáticos es fundamental la existencia de unas instalaciones adecuadas. El porcentaje de éxitos actualmente es muy variable de unos centros a otros. Los islotes se deben disociar del tejido exocrino mediante enzimas, colagenasa y liberasa, y se visualizan con colorante. Entonces se procede a su separación mediante gradientes de densidad hasta obtenerlos con el mayor grado de pureza. Los islotes se inyectan en la porta mediante radiología intervencionista para su depósito final en la periferia del hígado. Este procedimiento no requiere anestesia general, y sus complicaciones, infrecuentes, son la trombosis portal o la hemorragia. La mortalidad es excepcional $^{2}$.

Los criterios de inclusión del receptor serían edad comprendida entre 18 y 65 años, complicaciones metabólicas frecuentes (hipoglucemias severas, hiperglucemias, cetoacidosis) que requieren atención médica, problemas clínicos y emocionales con la insulinoterapia que resulten incapacitantes para el paciente, fallo de la insulinoterapia para prevenir las complicaciones, niveles de péptido $\mathrm{C}<0,5$ $\mathrm{ng} / \mathrm{mL}$, índice de masa corporal $<28 \mathrm{~kg} / \mathrm{m}^{2}$, y una buena función renal con aclaramiento de creatinina $>70 \mathrm{~mL} / \mathrm{mn} / 1,73 \mathrm{~m}^{2}$.

Los análisis comparativos a tres años de la duración de la independencia a la insulina, niveles de péptido $\mathrm{C}$ y de $\mathrm{Hb} \mathrm{Alc}$ son significativamente mejores para el trasplante completo de páncreas. Por ello, se recomienda que los pacientes que tengan indicación reciban un trasplante de páncreas, y el resto un TIP. No obstante, existe la esperanza de que el trasplante de islotes sea la técnica del futuro, una vez se hayan superado sus obstáculos.

\section{BIBLIOGRAFÍA}

1. Stegall MD, Larson TS, KudVa YC, Grande JP, NYBERG SL, PRIETO M et al. Pancreas transplantation for the prevention of diabetic nephropathy. Mayo Clinic Proc 2000; 75: 4956.

2. Revista española de Trasplantes 2005; 14 : 207-251.

3. Transplantation of the pancreas. Rainer W.G. Gruessner, David E.R. Sutherland. Ed. Springer, 2004.

4. Demartinesa N, Schiessera M, Claviena PA. An evidence-Based Analysis of simultaneous plancreas-kidney and pancreas transplantation alone. Am I Transplant 2005; 5: 26882697.

5. Pancreas and islet transplantation. Hakim N, Stratta R, Gray D. Ed. Oxford Universiy Press, 2002.

6. KAHL A, Bechstein WO, Frei U. Trends and perspectives in pancreas and simultaneous pancreas and kidney transplantation. Curr Opin Urol 2001; 11: 165-174.

7. International Pancreas Transplant Registry. Ed. B. J. Bland, Minneapolis, Minesota, USA. http://www.iptr.umn.edu.

8. Sutherland DER, GRUESSNER RWG, DunN DL, MATAS AJ, KANDASWAMY R, MAUER SM et al. Lessons learned from more than 1000 pancreas transplants at a single institution. Ann Surg 2001; 233: 463-501.

9. Venstrom J, McBride MA, Rother KI, HIRSHBERG B, ORCHARD TJ, HARLAN DM et al. Survival after pancreas transplantation in patients with diabetes and preserved kidney function. JAMA 2003; 290: 2817-2823.

10. NATHAN DM. Isolated pancreas transplantation for type 1 diabetes. JAMA 2003; 290: 2861-2863.

11. GAGLIA JL. The state of islet transplantation. Curr Opin Endocrinol Diabetes 2006; 13: 199204. 